\title{
Mirada retrospectiva al carácter social del diseño gráfico en las organizaciones de la sociedad civil de México
}

\section{Retrospective insight at the social nature of graphic design in civil society organizations in Mexico}

\author{
María del Mar Sanz Abbud \\ marimar.sanz@ibero.mx \\ Universidad Iberoamericana, Ciudad de México-Tijuana \\ Ciudad de México, México
}

ORCID 0000-0002-2753-0904

Recibido: 07 de marzo de 2019

Aprobado: 02 de junio de 2019

Publicado: 01 de julio de 2019

\section{Resumen}

Este artículo se deriva de la investigación doctoral realizada sobre un recorrido histórico del diseño gráfico y su interrelación con las Organizaciones de la Sociedad Civil (osC) en México. Esta reflexión, de carácter longitudinal, tiene como finalidad dar muestra de la función del diseño en ámbitos sociales y civiles. Las interrogantes que motivaron tal planteamiento fueron saber acerca de cuál y cómo ha sido el papel del diseño gráfico en las osc. A lo largo de la historia, es posible dar cuenta de las diversas concepciones del diseño. Una de estas nociones es aquella comprendida a través de la mirada sobre la relación del diseño y las osc. Para tal propósito se revisaron diferentes temporalidades, que abarcan desde el período del Virreinato de Nueva España hasta la primera década del siglo XXI. Esta revisión tiene como objeto además, comprender la sintaxis y práctica de la imagen de los códigos y el lenguaje visual en el ámbito social y civil.

Palabras clave: diseño gráfico, estudio longitudinal, interrelación, osc, carácter social.

\section{Abstract}

This article is derived from the doctoral research carried out on a historical journey of graphic design and its interrelation with Civil Society Organizations (osc) in Mexico. This reflection, of a longitudinal nature, aims to show the role of design in social and civil environments. The questions that motivated this approach were to know about what and how has been the role of graphic design in the osc Throughout history, it is possible to account for the various conceptions of design. One of these notions is that understood through the gaze on the relationship of the design and the osc. For this purpose, different temporalities were reviewed, ranging from the period of the Viceroyalty of New Spain to the first decade of the twenty-first century. The purpose of this revision is also to understand the syntax and practice of the image of codes and visual language in the social and civil environment.

Keywords: graphic design, longitudinal study, interrelation, osc, social character. 


\section{Las Organizaciones de la Sociedad Civil en México}

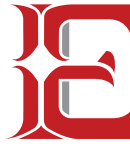

n México, de acuerdo con Villalobos y Cortés (2015), el Esta do-Nación está conformado por tres sectores: el primero es el Gobierno; el segundo es el lucrativo; y el tercero es el no lucrativo. Este último, comprende aquellas instituciones libremente emanadas de la sociedad civil, sin ánimo de lucro y cuyo objetivo es trabajar por el bienestar común. Estas pueden expresar la preocupación ciudadana, exigir la acción responsable de los funcionarios públicos, promover el acuerdo entre los integrantes pertenecientes a una comunidad, dar algún tipo de asistencia social y, en general, fomentar aquellas condiciones que favorezcan la calidad de vida.

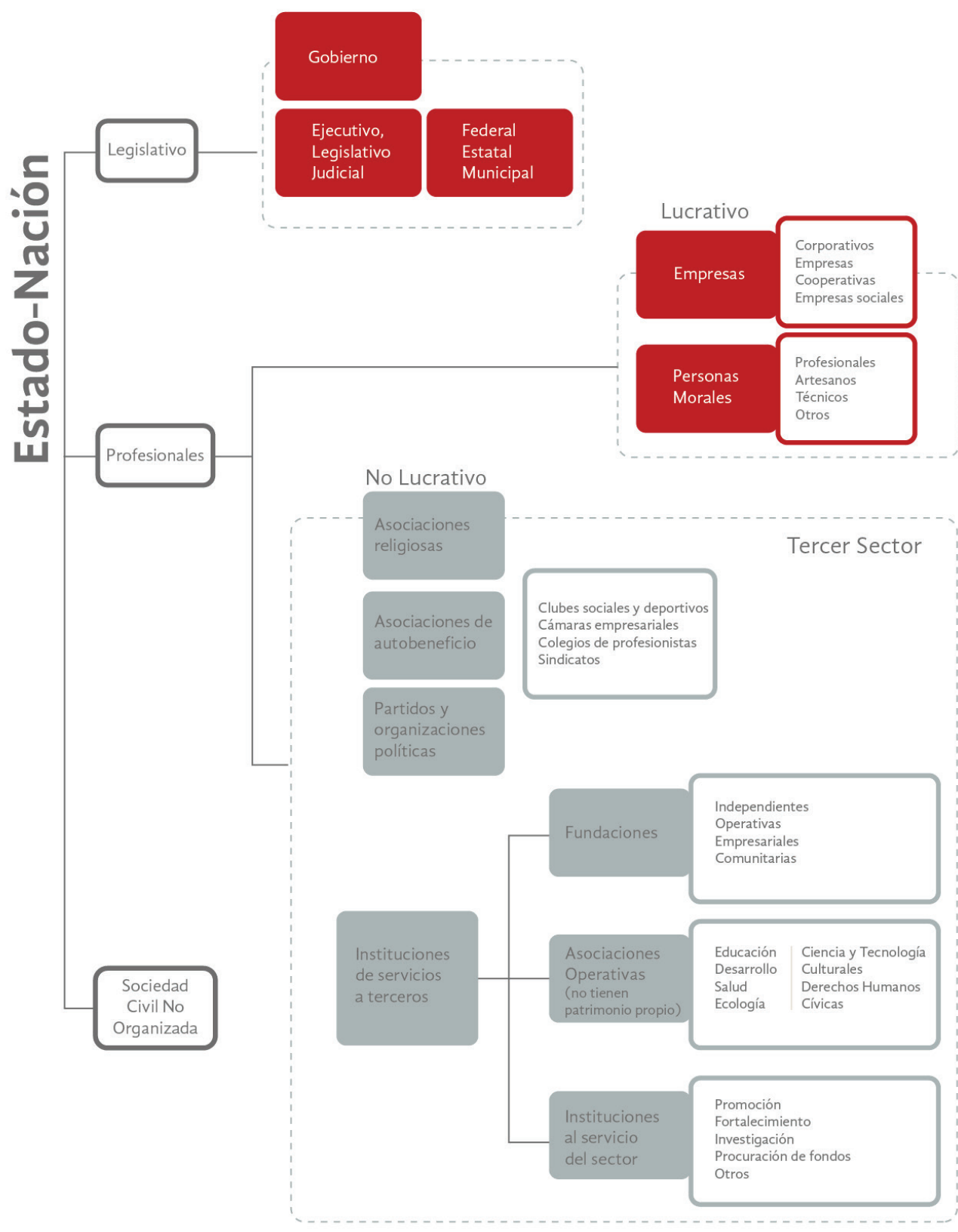

Figura 1. Estructura de sector no lucrativo

Fuente: Campedio estadístico del sector lucrativo(Villalobos y Cortéz. p. 16.2015 
Dentro de este tercer sector, el no lucrativo, se ubican las Organizaciones de la Sociedad Civil (OSC), también denominadas como «organizaciones de promoción social y desarrollo» (Valenzuela, 2012 y Verduzco, 2003). Generalmente, son conocidas como Organizaciones no Gubernamentales (ONG), y en México se estima existen más de veinte mil. Para fines de esta investigación, se apegará a la definición brindada por la asociación civil, Centro Mexicano de Filantropía (CEMEFI), el cual define como: «[un conjunto de] ciudadanos que actúan colectivamente para defender alguna causa o interés común que se caracterizan por estar voluntariamente organizados, ser autónomos, no formar parte del gobierno o del mercado y no tener fines de lucro» (Cortés, Martínez, Sánchez, Adame y Winkel, 2011, 17). En la figura 1 se puede observar la conformación de Estado-Nación y el tercer sector referente a las OSC o Instituciones de Servicios a Terceros.

Estas agrupaciones, conformadas en su mayoría por equipos interdisciplinarios, funcionan como un puente entre la ciudadanía y el gobierno. Por esta razón, se puede hablar de un desarrollo implícito en la constitución del Estado. Una de las acciones esenciales de una osc es la participación ciudadana, a partir de la cual, establecer una relación de comunicación con el gobierno. Por lo que, vistas desde un punto estructural-operacional sus características son: (a) organizaciones estructuradas, (b) privadas, (c) sin fines de lucro, (d) independientes, (e) voluntarias (Salamon, Anheier, List, Toepler, \& Sokolowski, 1999).

Diseño de la investigación
Debido al carácter longitudinal de este análisis se realizó una investigación documental. A partir de la cual, recabar, comparar y comprender la interrelación del diseño gráfico en las osc. Se observó una correlación entre los sucesos históricos y las concepciones gráficas referentes a un determinado momento histórico del país. Respecto al estudio de las osc, los antecedentes en esta área del conocimiento se encuentran los trabajos de Valenzuela (2012), Verduzco (2003) y Villalobos (2010). Concerniente al desarrollo histórico del diseño gráfico anteceden los trabajos de Troconi, 2010 y Vilchis, 2010.

Es importante anotar que la investigación histórica del diseño es relativamente joven (ver Cross, 1999). Sin embargo, las aportaciones documentadas permitieron comprender el quehacer y la construcción epistemológica del diseño dentro del marco social. Mediante esta entender cómo es esta interrelación (Cross, 2006; Findeli, 2010; Herrera, 2010; Manzini, 2015; Margolin, 2005).

La metodología consistió en una investigación del diseño que al estar inmersa en un ecosistema donde interactúa con otros actores y factores, permitió generar nuevos conocimientos (Manzini, 2015). El planteamiento rector de esta investigación buscó responder al cuestionamiento acerca de cuál y cómo ha sido el carácter del diseño gráfico en las osc, dichas interrogantes marcaron la ruta de explo- 
ración para reflexionar sobre la pertinencia y las acciones aplicables posteriormente en el sector no lucrativo.

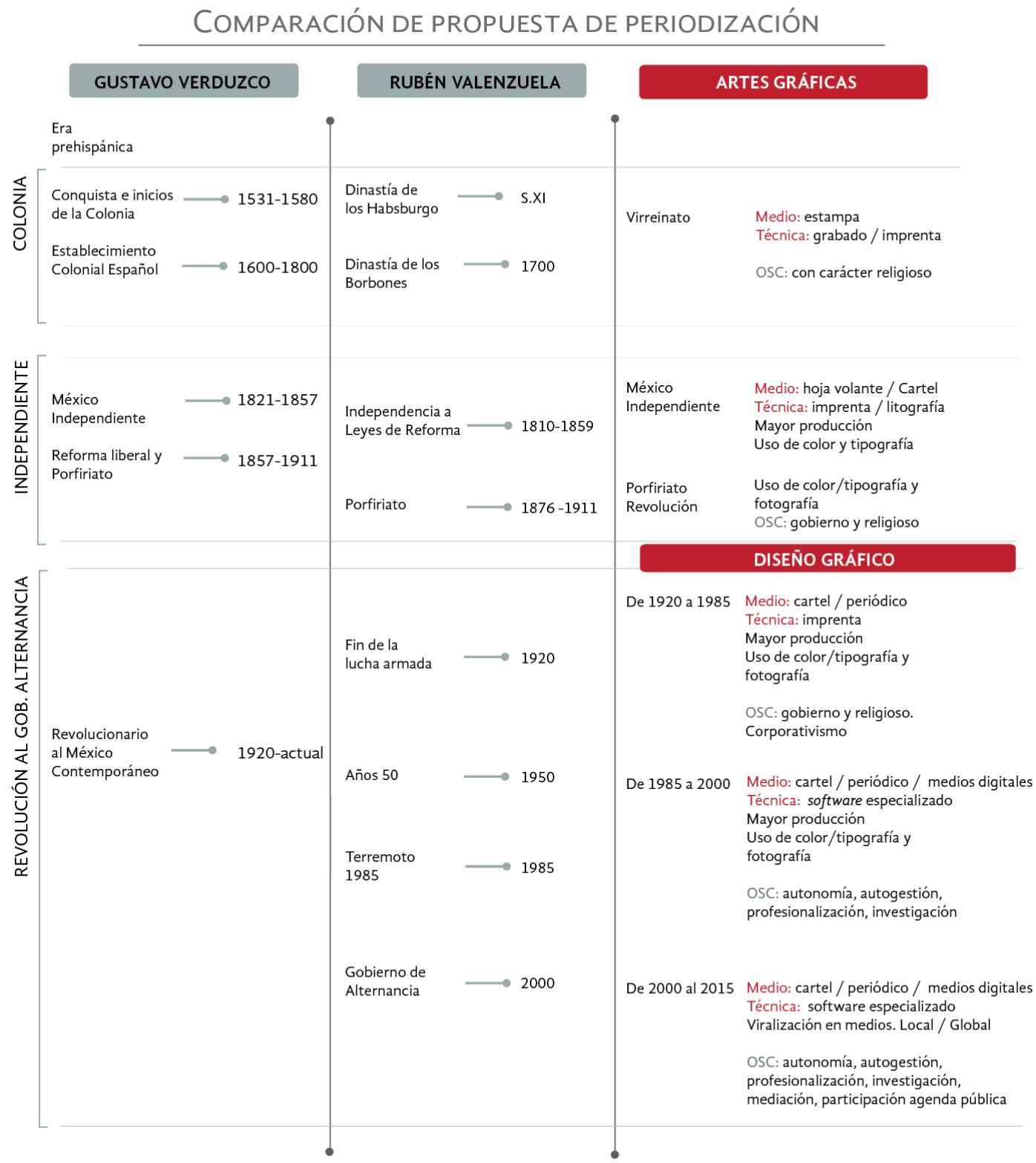

Figura 2. Relación de la evolución histórica de las OSC paralela a la del Diseño Gráfico Fuente: basada en Sanz, 2017; Troconi, 2010; Valenzuela, 2012; Verduzco, 2003; Vilchis, 2010

Para efecto de esta investigación, se estructuró el desarrollo de la información en tres partes, centrado en la evolución histórica del diseño gráfico paralelamente al de las osc. Este quedó comprendido por los períodos denominados: México virreinal, México independiente, México revolucionario al México contemporáneo. Ya que, por medio de tal exposición se logró entender el carácter social del diseño considerando las vanguardias artísticas, el uso de elementos sintácticos y pragmáti- 
cos, y los medios de producción (Sanz, 2017). En la figura 2 se muestra la relación el diseño gráfico y las osc de México.

- El diseño gráfico en las organizaciones de la sociedad civil México Virreinal. La imagen, un medio de cohesión social
El período previo al Virreinato de Nueva España se considera un tiempo de confrontación y de reajuste sociocultural. Principalmente a causa del proceso colonizador de los conquistadores españoles, los constantes levantamientos indígenas y las enfermedades provocadas por epidemias. Esto trajo consigo por un lado, el desplazamiento de comunidades y un consecuente cambio de vida, entre estos, la pobreza y el desamparo de la población; por otro lado, se iniciaron labores sociales por parte de personas y de instituciones enfocadas en la protección de los indígenas. Tras el arribo de las misiones coloniales españolas, se llevaron a cabo entre el siglo XVI y el siglo XVIII el establecimiento de instituciones para la asistencia social (véase Verduzco, 2003).

La fundación de estas instituciones de apoyo solidario constituyeron tres modelos integrados por: hospitales, escuelas y cofradías. Estas últimas se han considerado como el origen de las osc actuales. Las cofradías ejercieron un papel importante, pues eran un vínculo entre los diferentes espacios: social, económico, cultural y político. De acuerdo con Verduzco: «Cumplieron como instrumentos de evangelización, de integración social [...] y apoyo solidario» (Verduzco, 2003, 13).

En un principio estas cofradías se caracterizaron por la heterogeneidad de sus afiliaciones, actividades sociales y económicas. Estuvieron conformadas por diferentes grupos de seglares, los cuales adoptaban reglas de convivencia y eran reguladas por la iglesia para promover la vida cristiana en la comunidad. A través de la expedición de patentes y sumarios de indulgencias (Bazarte y Gacía, 2001): el cofrade daba a conocer su pertenencia a una determinada cofradía. Esto significaba la asunción de derechos y responsabilidades, como podría ser la caridad hacia el prójimo. La patente cumplió diversas funciones, por ejemplo, el culto religioso, mediante el cual expresar una devoción y un fervor. Debido a que, se contemplaba en ella un camino para el alivio material y espiritual, esto al ser visible y palpable generando así un vínculo de protección.

El uso de la imagen religiosa -la cual se convirtió en signo de la conquista espiritual- estuvo presente en espacios públicos y privados. Su carácter regulado por parte de las cofradías, fue una forma de comunicar la ideología y valores de la sociedad novohispana. Las diferentes representaciones iconológicas fueron en un inicio un medio para la evangelización de los pueblos indígenas, y después, un apoyo para la conformación de la sociedad novohispana. (Gruzinski, 1994) refiere que los indígenas adoptaron la imagen religiosa europea para la expresión de su nueva fe e identidad, símbolo de una comunidad, dichas representaciones constituyeron también un nexo social y cultural bajo el dominio español. Por su parte, Sanz $(2017,68)$ señala que «la patente permitió borrar las divisiones sociales, económicas y políticas. Construyó un vínculo activo entre 
la comunidad y funcionó como un medio de propagación y pensamiento colectivo». De esto, se puede inferir una síntesis visual en la cohesión social y cultural por medio de las cofradías. En la figura 3 se da muestra de dos casos: una patente y un sumario.
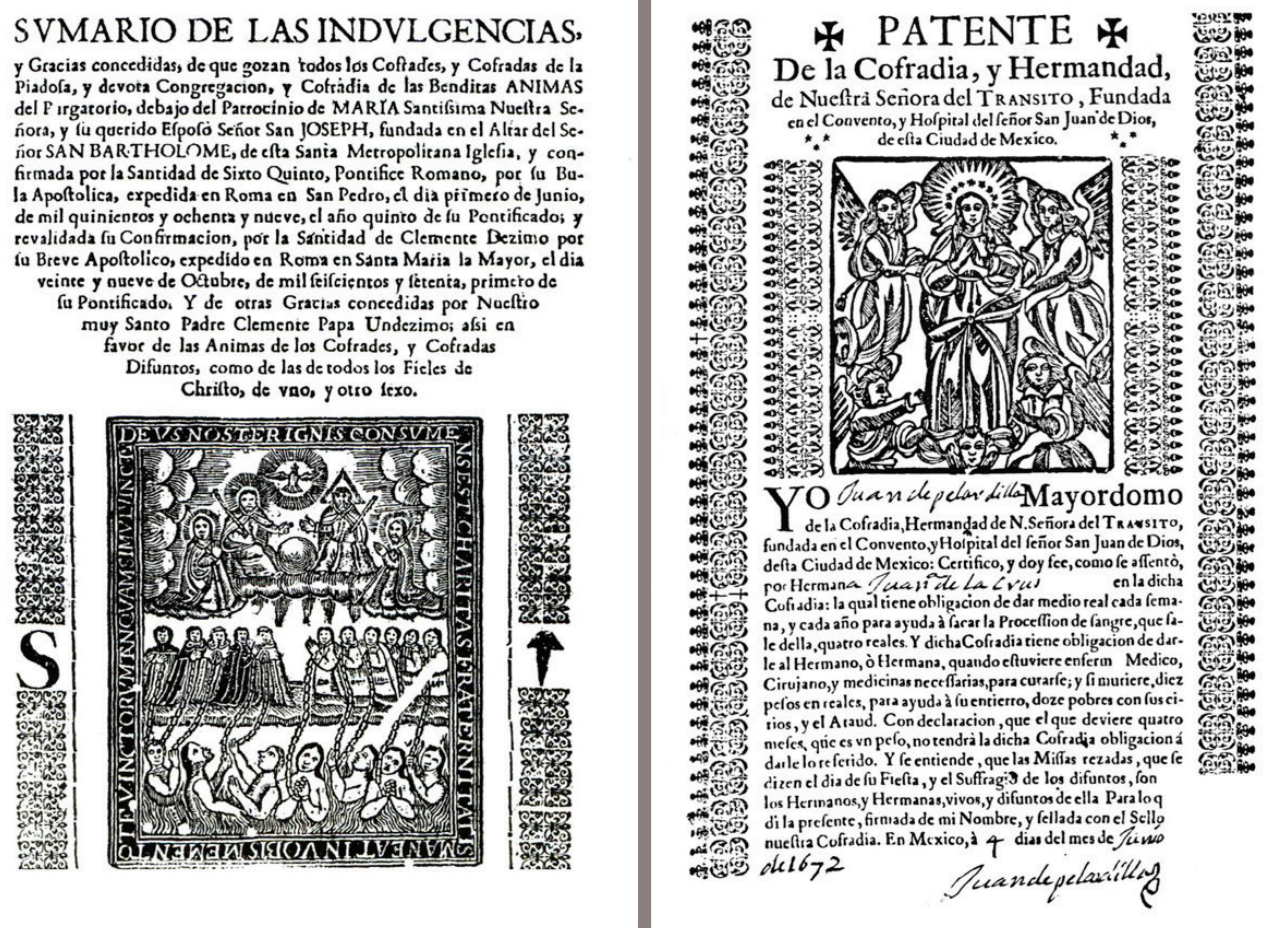

Figura 3. Sumario de las indulgencia Cofradía de las Benditas Ánimas, y

Patente de la Cofradía, y Hermandad de Nuestra Señora del Tránsito

Fuente: Bazarte y García, 2001.

\section{- El diseño gráfico, un medio para en la creación de una identidad nacional}

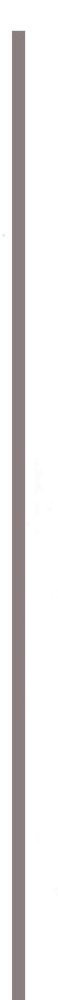


católico fue fundamental, esto en contraposición de los países con religiones protestantes. Debido a que, puede hablarse de una relación cercana entre la filantropía y las reglas que normaron las cofradías. Como fue señalado, el carácter laico abrió espacios a filántropos en las tareas de asistencia social a partir de un marco jurídico que alentó su desarrollo. No obstante, el sistema autoritario ejercido por la Iglesia durante el Virreinato, generó un rasgo paternalista que marcó la relación entre organizaciones y ciudadanos. Esta condición, retardaría el tiempo de evolución hacia la acción social y autónoma como instituciones.

El paso hacia esta conformación social y autónoma se alcanzaría hasta mediados del siglo Xıx, durante la presidencia de Benito Juárez y la promulgación de las Leyes de Reforma, las cuales establecieron la separación de la Iglesia del Estado. Estas acciones marcaron una función para las organizaciones sociales y el gobierno asumió sus responsabilidades, pues se creía que «Las nuevas ideas, propias del liberalismo asignan un papel importante a los individuos - a los filántropos- en las tareas de asistencia social [...] las nuevas leyes proporcionan un marco jurídico que alientan su desarrollo» (Valenzuela, 2012, 95).

En 1833 se creó la Dirección General de Beneficencia Pública, pero los problemas económicos aquejados en el país no permitieron que el gobierno diera un completo seguimiento. Por lo que, debió consentir que las organizaciones sociales fueran retomadas por instituciones religiosas o al cobijo de empresarios en el país. Referente las artes gráficas en este período se puede hacer la mención de las hojas volantes «Medio de difusión popular durante el siglo XVI al XVII» (Bancomer, 2013). Así como de, carteles los cuales contenían imágenes e ilustraciones, colocados por lo general en plazas públicas.

A finales de siglo Xıx, durante el período presidencial de Porfirio Díaz comprendido de 1876 a 1910 el país logró una estabilidad política. Esto permitió un crecimiento económico, se impulsó la industrialización, la urbanización e innovación tecnológica. Pero la distribución de la riqueza fue desigual. A su vez, se experimentó un crecimiento de las beneficencias públicas y privadas, sociedades mutualistas, esto es, una institución sin fines de lucro, regida por el precepto de la asistencia mutua entre sus integrantes, los cuales trabajan de manera coordinada y solidaria para brindar servicios a los miembros de la asociación, suelen financiarse a través de las contribuciones o cuotas de sus socios. Otro caso por mencionar, fue el de la instauración den la Lotería Nacional para la Asistencia Pública, encargada de la celebración de sorteos con premios en efectivo, destinados a captar dinero para apoyar económicamente al titular del Poder Ejecutivo en los asuntos orientados a procurar la igualdad entre aquellos mexicanos sin posibilidad de satisfacer por sí mismos sus más urgentes necesidades (Lotería Nacional de México, 2010). 
La gráfica desarrollada durante este contexto aportó matices de carácter particular, en la construcción de una identidad nacional. Acorde con Troconi, (2010, 17-29):

José Guadalupe Posada fue célebre por sus dibujos de escenas costumbristas, folclóricas, de crítica socio-política y por sus ilustraciones de calaveras. Su trabajo le valió la aceptación y admiración popular, por su sentido del humor, propensión a lo dramático y calidad plástica. Posada retrató las creencias y formas de vida cotidiana de los grupos populares, criticando los abusos del gobierno y la explotación del pueblo. Antonio Vanegas Arroyo fue el editor más popular de gacetas callejeras, corridos, historietas, adivinanzas y publicaciones varias de su momento. Manuel Manilla, caricaturista, su figura se ha visto eclipsada por José Posada, quién adquirió fama a partir de sus grabados relativos a la muerte en un tono festivo. Cabe señalar que Manilla - hasta donde se sabe-fue el primero en realizar grabados en donde se humanizaba y caricaturizaba a la muerte. De esta manera, la influencia que recibió Posada, fue directa, ya que ambos trabajaron en el taller de Antonio Vanegas, posteriormente Posada supliría a Manilla.

Las artes gráficas producidas en este contexto combinaron sincréticamente, las raíces prehispánicas y la herencia española (Sanz, 2017). Se logró el aumento en el material editorial a través de la producción de: serie de libros, periódicos, carteles y hojas volantes. También se debe distinguirse la utilización constante del color y el manejo tipográfico, como indica Bonilla (Troconi, 2010, 28):

Las aspiraciones de progreso tenían como paradigma a países como Inglaterra y Francia [...] la empresa editorial, junto con la ilustración gráfica, conoció continuas innovaciones que le permitieron alcanzar un público mayor [...] Estas transformaciones llegaron tarde a México, donde cobraron un desarrollo propio.

Este desarrollo proporcionó un mayor espacio para la crítica, antes restringida por el gobierno o por la Iglesia. En la élite se dio un afrancesamiento, notorio en los espacios gráficos. Mientras que, en los centros urbanos las publicaciones populares hacían gala de un sentido humorístico, «la risa empezó a ser un arma contra el régimen [...] mediante la figura editorial: el periodismo poco-serio» (Sillar citado por Troconi, 2010, 35). La producción editorial permitió que un mayor número de ciudadanos se informaran sobre los acontecimientos del país. Esto conllevó a una mayor participación en temas sociales (ver figura 4).

A inicios del siglo $x x$ el ambiente de descontento popular contra el presidente Porfirio Díaz, la ausencia de partidos políticos y la distribución económica desigual —sobre todo en sectores campesinos- sobrevino en el inicio de la Revolución Mexicana. 


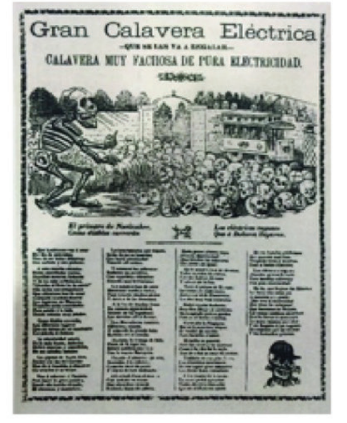

Hoja Volante

Gran Calavera Eléctrica Autor: José Guadalupe Posada

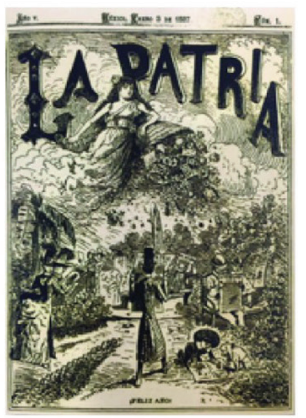

Periódico de Élite Periódico de Élite
LaPatria (1887)

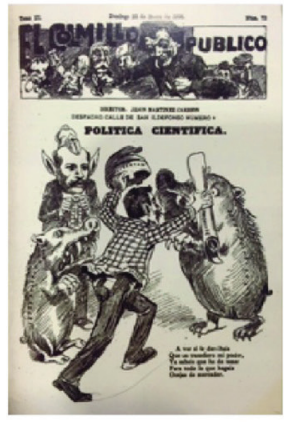

Periódico Popular Periódico Popular
El colmillo público (1905)

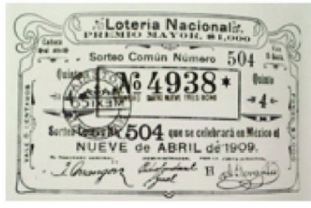

Billete de la loteria Nacional (1909)

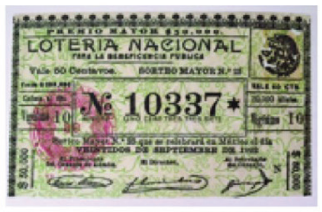

Billete de la lotería Nacional (1922)

Figura 4. Muestra de producciones gráficas comprendidas durante el período de 1821 a 1920

Fuente: Troconi, 2010 y Vilchis, 2010.

\section{(1) El diseño gráfico en la unificación política y social}

\section{México Posrevolucionario}

Después del fin de la Revolución Mexicana se conformó una nueva nación y un período de estabilidad que transitó hacia la democracia. Asimismo, se gestó un Estado, con un gobierno legítimo, el cual logró obtener el apoyo de los sectores más amplios de la sociedad. De igual forma, se formaron sindicatos y cooperativas en el sector obrero y laboral.

El gobierno se convirtió en benefactor social y cuyo propósito era atender las necesidades del pueblo, lo que conformó un sistema corporativista. Esto es, un forma de organización social, política y económica de tipo colectivista donde las unidades de decisión son corporaciones y no personas (existen diferentes tipos de corporativismos). Este sistema se utilizó mucho a finales de la Revolución Mexicana de 1929 a 1960. Debido a dos causas fundamentales: por una parte, a la necesidad de gobernabilidad, ya que esto garantizó por muchos años el mantenimiento de una relativa paz social y una cierta legitimidad en sus acciones; por otra parte, la necesidad que tuvo el Estado de constituirse como agente de desarrollo ante la falta de una burguesía nacional sólida capaz de hacer frente a la competencia de capitales internacionales. Para lograr tal propósito, requirió del apoyo de las organizaciones sociales, creadas y estimuladas verticalmente (desde arriba) mediante un proceso autoritario de institucionalización (Narváez, 2007).

En México, el Partido Revolucionario Institucional (PRI) cooptó y controló desde su creación al sector obrero, el sector campesino y el sector 
popular de la sociedad civil organizada. De manera que, se asegurarse el control político. La práctica del corporativismo solo reconoce como representantes legítimos de las organizaciones a campesinos y a la clase media. Además, estaban las organizaciones corporativas afiliadas al partido del Estado. Las prácticas de clientelismo (el otorgamiento de beneficio a cambio de apoyo político) y de cooptación (reclutamiento de líderes para coartarles su capacidad de iniciativa política) eran recursos frecuentes en la estructura corporativa del Estado mexicano (Cortés et al., 2011).

Estas acciones inhibieron el desarrollo de organizaciones independientes y autónomas que resultaran ajenas al gobierno, como expone Luis Lopezllera en 1988 (Valenzuela, 2012, 98):

El Estado mexicano ha mantenido una presencia hegemónica en toda la vida organizativa de la sociedad [...] vinculando todo esfuerzo de construcción social al partido «oficial» [...] quebrantando la autonomía de las iniciativas, tornándolas partidarias, gestando el objetivo de establecer un control político proselitista [...] una especie de corporativismo absorbente de los sectores populares que ha funcionado durante 60 años, manteniéndose sólo [sic] algunos sectores que escaparon de su influencia.

Durante este período, el diseño gráfico fue desarrollado con una orientación nacionalista (Vilchis, 2010). En este orden, de carácter cultural y educativo, se buscó un desarrollo social y la construcción de una identidad nacional. Artistas gráficos como: Gabriel Fernández Ledesma; Díaz de León; Gerardo Murillo Cornado, Dr. Atl; Fermín Revueltas o Adolfo Best Maugard, de la mano de las vanguardias como el dadaísmo, constructivismo, futurismo, impactaron en la construcción de este lenguaje gráfico. Mismo que sería articulado por Josep Renau, Miguel Prieto Anguita y Vicente Rojo, españoles exiliados, aportándole creatividad, técnica y compromiso social reflejo de los nuevos ideales, «propusieron la integración de diversas concepciones estéticas en un arte nacional que respondiera a la unificación política y social» (Troconi, 2010, 90). El resultado fue significativo para la sintaxis de esta gráfica, que además, alimentó la fantasía de una visión del progreso en la clase media y popular.

Pero cuál fue ese lenguaje propuesto para el desarrollo de esta sintaxis visual. Este diseño utilizó entre sus recursos: las formas geométricas con imágenes en alto contraste, tipografías con un peso visual marcado, colores primarios. Esto también fue posible a la reproducción obtenida mediante la técnica del grabado. La creatividad y la técnica empleada dieron como resultado un estilo de alto impacto visual y una comunicación legible. La gestión de esta nueva forma de realización gráfica se dio en diversos espacios como: ;30-30! comprendida de 1928 a 1930; la Liga de Escritores y Artistas Revolucionarios (LEAR) comprendida de 1933 a 1938; y el Taller de Gráfica Popular (TGP), cuyos principales promotores fueron Leopoldo Méndez, Pablo O'Higgins y Luis Arenal. Estos 
tres espacios sirvieron como medios para la difusión de los problemas políticos y sociales del país. La mayoría de sus integrantes fueron militantes del partido comunista. Entre sus publicaciones se encuentran El Machete, Frente a Frente y El Crisol (Troconi, 2010). Referentes para la discusión política y social del discurso visual (ver figura 5).
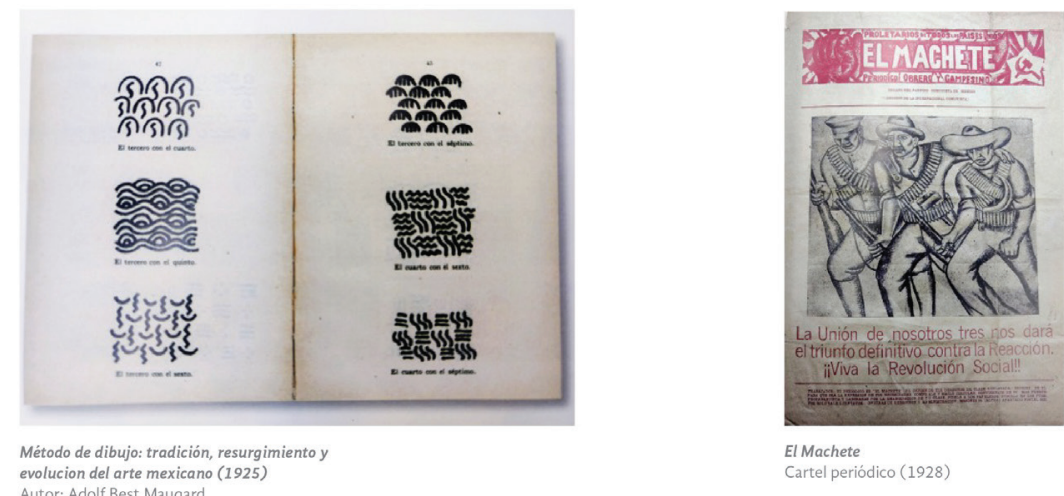

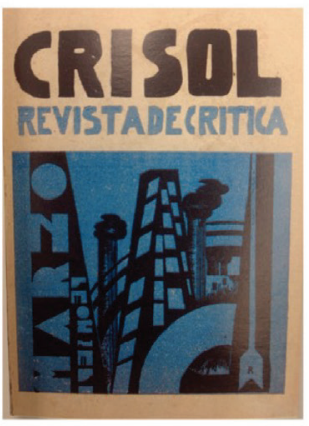

Revista Crisol

Portada de Revista (1929-1930)

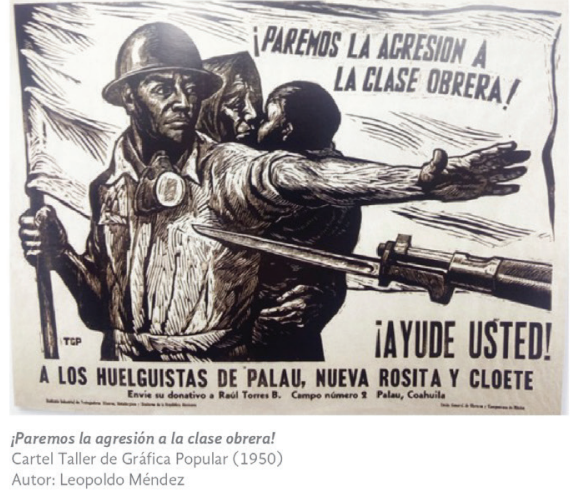

Autor: Leopoldo Méndez

Figura 5. Producciones gráficas del período comprendido de 1920 a 1950 Fuente: Troconi, 2010; Vilchis, 2010.

El diseño gráfico con una postura activista: los años sesenta y setenta
Durante los años sesenta, una serie de sucesos sociales como que el sistema corporativista, establecido por el Estado, dejara de ser eficiente en la resolución de los problemas que aquejaban al país. Aunado a un crecimiento demográfico en las ciudades, provocó una demanda de servicios para la cual el Estado no estaba preparado. Condujeron al surgimiento de movimientos urbano-populares y a que organizaciones adoptaran de una postura activista para lograr un cambio social. Las organizaciones se reestructuraron en dos vertientes: aquellas que continuaron con la asistencia del prójimo, conformadas por el sector privado y ciertos grupos de la Iglesia; y aquellas otras que, asumieron ciertos grupos de la Iglesia y organizaciones políticas al margen de los partidos (Cortés et al.).

Fue en este entorno de cambios socioculturales (las exigencias no cubiertas del gobierno, el debilitamiento del nacionalismo y el deterioro de 
la relación Universidad-Estado) que surgió el movimiento estudiantil de 1968 (Barragán, 2008), el cual culminó en la Plaza de las Tres Culturas de Tlatelolco tras la reprimenda por parte del grupo paramilitar Batallón Olimpia y el Ejército Mexicano. Este suceso dañó la legitimidad del Estado y contribuyó al desarrollo de una actitud crítica en diversos sectores de la sociedad.

Concerniente a la producción gráfica de este marco cultural, se realizó un planteamiento con recursos como las metáforas visuales, a partir de las cuales, se denunciaron los abusos del gobierno. Esta gráfica se elaboró principalmente por estudiantes de la Escuela Nacional de Pintura, Escultura y Grabado (ENPEG) y de la Escuela Nacional de Artes Plásticas (ENAP). Los medios de difusión que utilizaron fueron panfletos, carteles, hojas volantes, mantas, pancartas; la reproducción de estos fue a través del linóleo, la serigrafía, el esténcil, y en menor proporción, el offset y el fotograbado. Habría que decir también que fueron retomados algunos elementos gráficos de los Juegos Olímpicos de México 1968 para denunciar la realidad que acontecía en el país (ver figura 6).
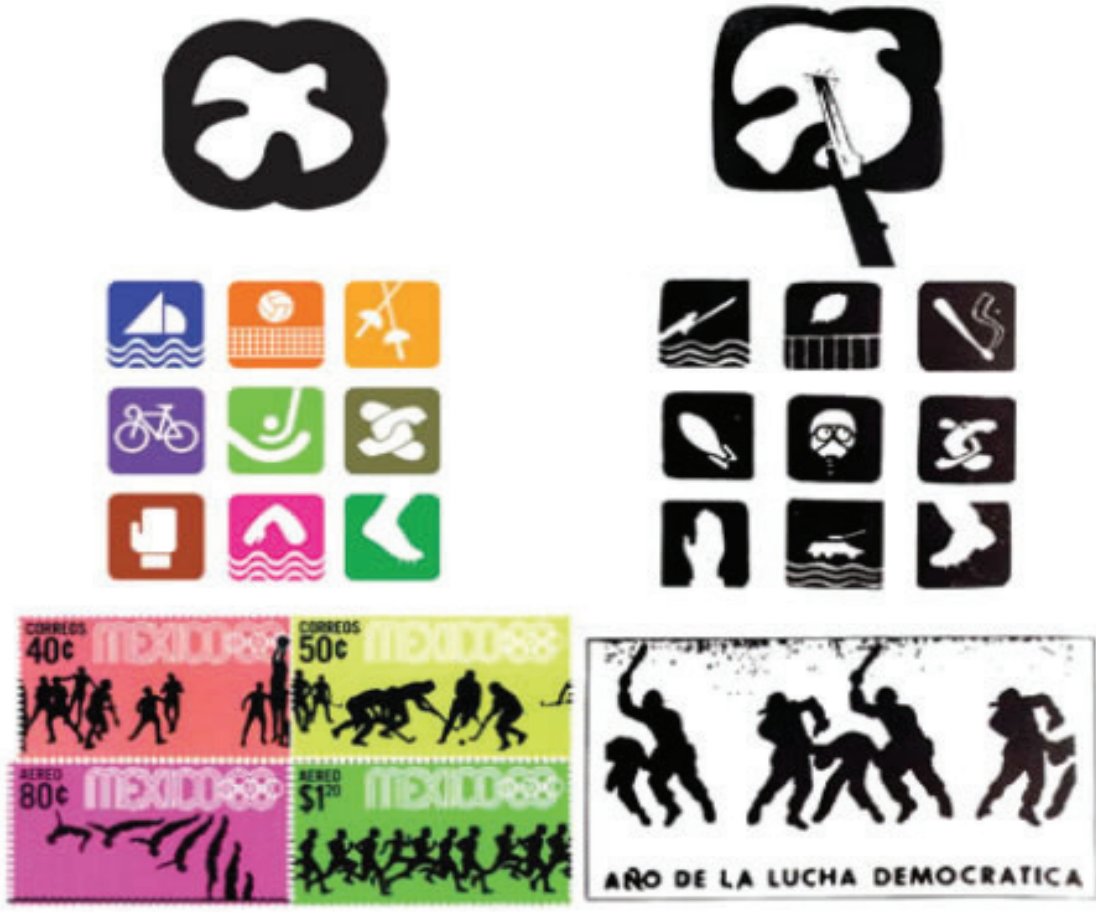

ARO DE LA LUCHA DEMOCRATICA

Figura 6. Producciones gráficas de los Juegos Olímpicos de México 1968 y la intervención en algunos elementos gráficos hecha por el Movimiento del 68 Fuente: Troconi, 2010.

La enseñanza del Diseño Gráfico como una disciplina en las universidades comenzaría hasta en siglo xx, tras las bases que sentara la Escuela Bauhaus en el diseño. Aunque se puede inferir, en una tradición del diseño anterior desarrollada por artistas y artesanos del oficio comprendido de las artes gráficas. Estos aprendían el oficio en espacios en los cuales 
los conocimientos era sobre todo de orden técnico, conformado por códigos del lenguaje gráfico. Uno de los medios con mayor difusión fue el cartel, ideal entre los jóvenes, quienes realizaron una producción gráfica de oposición al gobierno en la que se podía leer: Acción proletaria, basta, brecha, combate. También se creó el «Movimiento de los grupos» que cuestionó la situación política con una postura única frente a los movimientos sociales que buscaban reformas en los ámbitos de la educación, las organizaciones sociales y sindicatos a través de diferentes medios de expresión. Sus realizaciones se identificaron por su frescura e imaginación a través de nuevos medios y alternativas en su presentación visual (Troconi, 2010).

Evolución, del diseño análogo al diseño digital y la autonomía de las OSC
En los años ochenta se dieron cambios importantes en la estructura sociocultural de México. La primera debido a, la crisis económica la cual provocó el empobrecimiento de la clase media y popular. La segunda a consecuencia del sismo de la Ciudad de México. El último porque, el proceso electoral de 1988 marcó la vida social y política del país (Cortés et al., 2011; Valenzuela, 2012; Verduzco, 2003).

Se establecieron los primeros encuentros entre las diferentes organizaciones no lucrativas, lo que permitió poner en perspectiva la situación social del país entendida desde diversas miradas. No obstante, a los contrastes y las resistencias, se buscó emprender acciones en común, de acuerdo con la esencia de cada organización. Según Reygadas, en esta diversidad se identificaron tres tipos de acción: asistencial, filantrópica y de promoción del desarrollo (Cortés, et. al.).

En este período se dio una otra revolución tecnológica aunada a la globalización, lo que transformó todos los ámbitos (Castells, 2001). En el caso del diseño, con la llegada de la autoedición se experimentaron procesos más rápidos en la producción del diseño nunca antes logrados. Esto transformó y aceleró los procesos de producción, pero también dañó la identidad del diseñador gráfico, pues facilitó que cualquier persona con un equipo de cómputo generara diseños a bajo costo sin haber adquirido los saberes del profesional del diseño quien genera procesos de comunicación visual pertinentes (Troconi, 2010; Vilchis, 2010).

El primero de enero de mil novecientos noventa y cuatro en el municipio de San Cristóbal de las Casas, Chiapas se dio el levantamiento del Ejército Zapatista de Liberación Nacional (EZLN) contra el Ejército Nacional (La nueva Televisión del Sur, 2016). Suceso en el cual la participación de las osc fue importante, ya que su intervención facilitó el proceso de paz, al mismo tiempo que se legitimó la lucha por el desarrollo, el respeto de los pueblos indígenas y de la diversidad cultural. En cada movimiento social, la gráfica ha estado presente y en este caso concreto, se logró comunicar por medio de esta la mirada del otro y dejó evidencia del conflicto. Esta influyó en dicho contexto debido a las siguientes características que fue: espontánea, improvisada, diversa e inconsistente. Sin embargo, un rasgo distintivo fue que la gráfica zapatista es incor- 
poración y predominancia de la imagen indígena, pero no desde una perspectiva de víctima, sino en una actitud más activa, más propositiva, más digna (Hernández, 2004). Estos hechos coincidieron con la entrada en vigor del Tratado de Libre Comercio de América del Norte (TLCAN) lo que implicó una mayor participación de las organizaciones civiles en lo referente a derechos humanos.

Al finalizar el siglo $x x$, por fin las organizaciones lograron autonomía e independencia. Además de, la inserción y la participación en temas sociales e incidencia pública, así como mayor visibilidad. Estas diseñaron sus agendas, de acuerdo con su capacidad de respuesta técnica y profesional, tomaron un papel participativo ante diferentes problemáticas, más allá del asistencialismo. A partir de entonces, han obtenido recursos a través de los fondos públicos y beneficios fiscales, al reconocérseles como partícipes en la construcción del orden público.

Por otro lado, en el Diseño Gráfico - a pesar de que una mayoría promueve el desarrollo un lenguaje gráfico con valores estético para movilizar la demanda y para promover los mercados- se cuestiona acerca del ejercicio de diseñar como se da a conocer en el First Things First Manifesto 2000 (Pelta, 2012). De ello, surgió la vertiente del diseño social en el que un grupo de diseñadores se ha enfocado en las problemáticas sociales (Margolin, 2005). Así mismo se abrieron nuevas posibilidades de acción para colaborar de manera interdisciplinaria en otros espacios. En México, se ha iniciado una pequeña participación dentro del campo social. Aunque se estima que esta crecerá cuando tenga mayor injerencia, con fundamentos teóricos y el resultado de acciones.

\section{El diseño gráfico y México contemporáneo las organizaciones de la} sociedad civil Al dar inicio el siglo XXI, la elección presidencial de México fue ganada por el candidato del Partido de Acción Nacional (PAN), Vicente Fox Quezada. Este acontecimiento motivó la organización de acciones a favor de la democracia por parte de la ciudadanía, y se estrecharon las relaciones entre las osc y el gobierno. Durante este período se visualizó un cambio sobre la constitución de las organizaciones, ya que fue reconocida como un actor importante en la sociedad.

Este acercamiento entre las organizaciones y el gobierno posibilitó el diálogo en el que se definieron las funciones sobre las cuales trabajar cada uno desde su trinchera para la construcción del espacio público sin perder su identidad ni responsabilidad. Desde entonces, se han buscado mecanismos para trabajar de forma conjunta y enfrentar los retos hacia el bien común. Por primera vez, se realizaron acciones de trabajo colaborativo, a través de mesas que proponían planes y acciones que fortalecieran a las organizaciones ciudadanas. El discurso del gobierno hizo 
hincapié en la importancia de trabajar en unidad y con una responsabilidad compartida, labor que no ha sido sencilla. Pero inició un cambio en la forma de pensamiento en ambos espacios.

Las osc dejan en claro que no se identifican ni con el gobierno ni con el mercado. Su fin no persigue lucro alguno, sino el bienestar social. Aunque, sí realizan aportaciones a la economía social. Las personas que colaboran dentro de estas instituciones sociales son activistas sociales, estas suelen no estar motivados por el factor económico. Por otro lado, se percató pocas mediciones de datos estadísticos, indicadores e instrumentos por parte de las mismas organizaciones y del gobierno que informen sobre la cuantificación de recursos económicos y humanos.

Acerca del Diseño Gráfico, se ha observado una mayor injerencia en temáticas sociales, se exploran nuevas áreas de acción y se visualizan competencias que posibiliten la generación de alternativas ante problemáticas, lo que permite el reconocimiento y el valor de su aporte con sus quehaceres en lo social (Sanz, 2017). Una de las acciones más relevantes entre osC y gobierno (Valenzuela, 2012) se generaron tres líneas centrales de acción: (a) el establecimiento de un marco legal adecuado para el reconocimiento y regulación de las OSC, aprobándose la Ley de Fomento en la cual se inscribirían para ser reconocidas legalmente por el gobierno en el padrón del Instituto Nacional de Desarrollo Social (Indesol); (b) la creación de fondos y mecanismos financieros que apoyen la operación y los proyectos de las osc; (c) el diseño estrategias e instrumentos para su participación en políticas públicas. En los últimos años, el uso de las tecnologías de la información y comunicación (TIC) han posibilitado un espacio colectivo y amplificado que combina la participación a través del espacio físico y virtual, global y local (León, 2015). Debido a esto, se ha generado una mayor conciencia ciudadana, así como una participación más activa a través de las osc.

Se pueden mencionar algunas de las manifestaciones y movimientos sociales que se han presentado en estas dos últimas décadas, entre estos se encuentran: Iluminemos México, Ya Basta, Ni uno más, Acteal, Las muertas de Juárez, El problema del VIH, La discriminación, La equidad de género, Alto a la violencia, Yo soy \#132, Ayotzinapa. Algunos de estos han desaparecido, pero otros han sido semilla para la creación de nuevas osc. Por medio de la participación de estas asociaciones se ha logrado una mayor conciencia ciudadana e incidencia en la agenda legislativa para impulsar políticas y regulaciones. Como se ha señalado, la gráfica ha permitido generar un lenguaje visual que permite entender la esencia de cada una de estas OSC, su difusión y su participación. En la figura 7 se muestran las identidades visuales de los principales movimientos sociales. 

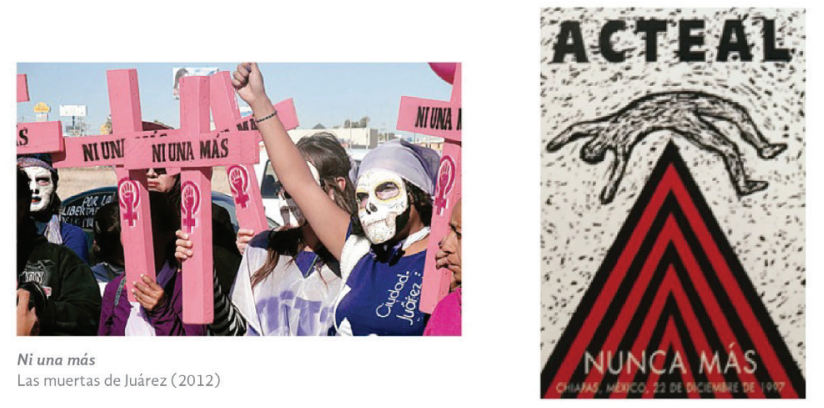

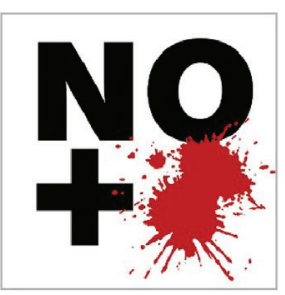

No más violencia (2011)

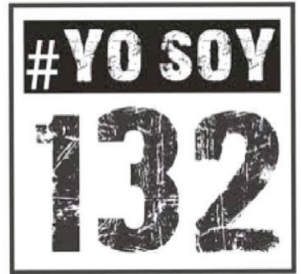

\#yosoy 132 (2012)

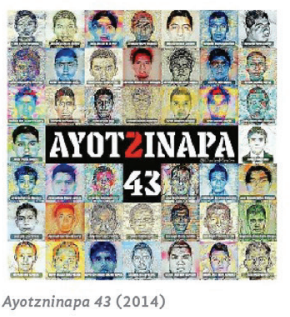

Figura 7. Identidades gráficas de los movimientos sociales de las primeras dos décadas del siglo XXI

Fuente: Animal político, 2019; Lo mejor de México, 2011; Twitter, 2013 y Troconi, 2010.

En los últimos 20 años, la formación del diseñador ha evolucionado, se le ha enseñado el uso de diferentes técnicas y medios para ejercer su oficio en los diferentes ámbitos. Al considerar los retos actuales, cada vez más complejos, el profesional del diseño ha de experimentar el formar parte de equipos interdisciplinarios con una visión estratégica para satisfacer una necesidad de comunicación visual en los diferentes entornos que engloban acciones. A pesar de los esfuerzos realizados en políticas públicas para impulsar la competitividad laboral que contemple la aplicación del diseño en cada uno de los ámbitos que contribuyen al desarrollo sustentable del país (Frias, 2008), no se ha logrado tener la participación que se ha pretendido.

El diseñador ha comunicado cada vez mejor el valor del diseño en la sociedad. Sin embargo, sigue pendiente, clarificar su actividad en los entornos sociales y civiles, si desea participar como un agente de cambio en pro del bien común del país. A esto habrá de sumarse que aunque las osc en México han realizado una labor importante en estos primeros 
decenios, aún hay áreas a las cuales atender. La ausencia de un impulso al fomento de las organizaciones a través de políticas públicas es evidente. Puesto que, se debe incrementar la gestión de recursos humanos y económicos; propiciar la participación ciudadana a través de estrategias para conectar, informar y promover la construcción colectiva dentro de un ecosistema, y estar interconectados en aras de apropiarse de las diferentes tecnologías de comunicación para estar presentes en la vida del ciudadano.

El diseño, en la vertiente social y civil, busca contribuir en la construcción de estrategias visuales para cumplir la función comunicadora de mejorar nuestras vidas. El diseño tiene una brecha de oportunidad al enfocarse al ciudadano. Cambiar la perspectiva, con enfoques en espacios diferentes, se convierte en desafío con la intención de que no termine en producción y distribución, sino en la promoción de cambios de comportamiento, para el buen vivir en sociedad.

- Conclusión En las páginas anteriores se expuso un recorrido histórico del heterogéneo grupo que conforman las osc en México. Este ha cambiado, de acuerdo con los diferentes eventos sociales, políticos, culturales y tecnológicos en el país, siempre condicionados por la evolución de nuestra historia como nación. A finales del siglo xx, dichas agrupaciones obtuvieron independencia y autonomía, lo que ha permitido realizar un papel determinante en la sociedad. Son un abanico de actores plurales y diversos que construyen una ciudadanía con distintas miradas y una diversidad de agendas. En los últimos veinte años, estos espacios han abierto espacios para el cambio y la innovación a partir de una visión global para situaciones locales.

Las osC son reconocidas como un sector independiente del gobierno y de la Iglesia. Su presencia y acciones cada día tienen mayor notoriedad. Poseen nuevas formas de intervención desde la participación de la ciudadanía, hasta propuestas de políticas públicas. Además, generan espacios de diálogo con los diferentes sectores para confrontar las diversas problemáticas en búsqueda de una sociedad democrática. Sin embargo, se reconoce que falta un abordaje desde otras disciplinas que podrían enriquecer este ámbito.

De forma paralela, se presentó un desarrollo del diseño gráfico en este recorrido histórico. A manera de una actividad presente y constante en la construcción de códigos visuales en los procesos de comunicación visual a través de los diferentes soportes, procesos y tecnologías acordes con cada época: de la patente de las cofradías a la hoja volante, de los carteles a las editoriales. El uso de las imágenes religiosas, el sincretismo entre la cultura prehispánica y española, el personaje clave de la catrina y el uso de la sátira a través de la caricatura presentada de modo improvisado en los formatos editoriales son algunos de los códigos. La gráfica desarrollada por el TGP, generó el estilo de una identidad nacional. Se reflejó a través del uso cromático, la tipografía con una marcado peso visual y la forma disponer a los personajes, acordes a los movimientos 
sociales que construyeron un código visual único. Este bagaje forma parte de la cultura material en la sociedad mexicana, presentando un estilo claro, creativo y propio, esto constata el aporte que ha tenido la disciplina en el desarrollo y evolución de las osc.

La participación del diseño social está presente en los movimientos sociales y políticos. Pero qué sucede con las organizaciones de la sociedad civil, por qué hay pocos registros sobre la disciplina en este ámbito. Esta exposición relacionó el diseño gráfico con las osc. Esto es, una primera mirada con la intención de construir una historia compartida. Pues casi siempre se presenta acotado a su área de acción. Esto alude hacia ese otro camino por recorrer para generar redes interdisciplinarias que aporten otros valores socioculturales y políticos.

Lo cierto es que generar saber en el diseño parte de una lectura sobre la sociedad con múltiples significados. El individuo juega a codificar y descodificar una diversidad de mensajes. Es ahí, donde el diseño se ubica, entre el entender y el traducir los elementos visuales; su cualidad particular es, tomar datos exactos y considerar los factores sociales.

Se sabe que las osc han enfrentado la falta de impulso del sector, procesos legales complicados para su registro, la privación de recursos para la realización de proyectos, y a esto se le suma el problema de cómo activar la participación ciudadana. De tal manera que, si se reconoce el aporte del diseño, conocimiento sobre la concepción de la forma en su sentido más amplio, este es un cohesionador de la cultura visual y material en la sociedad. Dado que, brinda y demanda una lectura de nuestro entorno y de los fenómenos actuales, con una mirada que imagina los posibles futuros. Por lo que, se exige tener un conocimiento sobre el impacto que causa el diseño en nuestro vivir cotidiano, centrado en el hombre. Entonces por qué son pocos los diseñadores expertos en este espacio. Dicho saber permitiría coadyuvar con acciones importantes en espacios civiles. Se busca la conformación de redes colaborativas. En lo particular, que el Diseño Gráfico contribuya en la construcción de mejores espacios sociales, que tanto se requieren en los tiempos actuales.

Animal político. (Junio, 2019). Gobernación pide perdón por feminicidios en Juárez. [Imagen]. Disponible en https://www.animalpolitico. com/2011/11/gobernacion-pide-perdon-por-feminicidios-en-juarez/

Bancomer, F. B. (2013). 100 años de calavera. Ciudad de México: Editorial RM México.

Barragán, P. M. (2008). El movimiento de 1968. Alegatos, 311-340. Disponible en http://www.azc.uam.mx/publicaciones/alegatos/pdfs/63/70-03.pdf

Bazarte, A., y Gacía, C. (2001). Los costos de la salvación. Las cofradías y la 
ciudad de México ( siglos XVI al XIX). (E. J. N. y R. G. Ochia, Ed.). México: Instituto Politécnico Nacional-Archivo General de la Nación.

Castells, M. (2001). Manuel Castells: Internet y la sociedad red. Programa de doctorat sobre la societat de la informació i el coneixement. Disponible en http://www.uoc.edu/web/cat/articles/castells/castellsmain7.html

Cortés, L., Martínez, C. B., Sánchez, G.; Adame, A., y Winkel, P. (2011). Una fotografía de la Sociedad Civil en México. México: Centro Méxicano de Filantropía e Iniciativa Ciudadana para la Promoción de la Cultura del Diálogo.

Cross, N. (2006). Designerly Ways of Knowing. London, UK: Springer Science+Business Media.

Desmet, P. M. a., \& Hekkert, P. (2007). Framework of 10. product experience. International Journal of Design, 1(1), 57-66. Disponible en www.ijdesign. org

Findeli, A. (2010). Searching for design research questions: some conceptual clarifications. Questions, Hypotheses \& Conjectures: discussions on projects by early stage and senior design researchers, 286-303. Disponible en https:// doi.org/978-1-45025-965-1

Frias, J. (Septiembre, 2008). El diseño de una política de diseño. FOROALFA. Disponible en https://doi.org/1851-5606

Gruzinski, S. (1994). La guerra de las imágenes. de Cristóbal Colón a «Blade Runner» (1492-2019 (Fondo de C). México: Fondo de Cultura Económica.

Hernández, A. G. (Enero, 2004). Comunicación horizontal, aporte esencial de la gráfica surgida en torno al EZLN. La Jornada. Disponible en https://www. jornada.com.mx/2004/01/11/011n1pol.php?origen=politica.php\&fly=1

Herrara, M. (Noviembre, 2010). Investigación y diseño: reflexiones y consideraciones con respecto al estado de la investigación actual en diseño. No Solo Usabilidad, 9. Disponible en http://www.nosolousabilidad.com/articulos/ investigacion_diseno.htm

La nueva Televisión del Sur. (Enero, 2016). Hace 22 años el Ejército Zapatista reivindicó los derechos indígenas. Tel Sur en Profundidad. Disponible en https://www.telesurtv.net/telesuragenda/22-anos-del-Ejercito-Zapatista-20141225-0008.html

León, A. (2015). Los nuevos movimientos sociales de México en el siglo XXI. Estudio exploratorio. Revista Espacios Transnacionales, 4(2007-9729).

Lotería Nacional de México. (2010). Lotería Nacional. Disponible en http:// www.lotenal.gob.mx/ 
Manzini, E. (2015). Cuando todos diseñamos. (P. Cattermole, Ed.). Madrid: Experimenta Editorial.

Margolin, V. (2005). La política de lo artificial. Ensayo y estudios sobre diseño. México: Editorial Designio. Disponible en https://di3prod.files.wordpress. com/2011/06/margolin-victor-las-politicas-de-lo-artificial1.pdf

Narváez, K. (2007). El Corporativismo Mexicano. Mexico D.F. Disponible en https://internacionalistanarvaez.wordpress.com/2013/05/14/el-corporativismo-mexicano/?blogsub=confirming\#subscribe-blog

Pelta, R. (2012, enero). Manifiesto First Things First ( 1964 ). Revista Temática de diseño . Asociación Cultural Monográfica, 1. Disponible en https://doi. org/2014-6604

Salamon, L. M., Anheier, H. K., List, R., Toepler, S., \& Sokolowski, S. W. (1999). Global Civil Society:Dimensions of the Nonprofit Sector. Lucrativo. (J. H. University, Ed.). Bilbao: Fundación BBVA. Disponible en http://www.fbbva.es/TLFU/dat/lasociedadcivilglobal.pdf

Sanz, M. del M. (2017). La contribución del diseño gráfico para promover la participación ciudadana en las redes sociales digitales a través de las Organizaciones de la Sociedad Civil en México María del Mar Sanz Abbud La contribución del diseño gráfico. Pontificia Universidad Católica de Rio de Janeiro. Disponible en http://www2.dbd.puc-rio.br/pergamum/tesesabertas/1313946_2017_completo.pdf

Troconi, G. (2010). Diseño gráfico en México, 100 años. 1900-2000 (Primera ed). Ciudad de México, Mexico: Artes de México, Universidad Autónoma Metropolitana.

Valenzuela, R. (2012). La Sociedad Civil en México. (Gobieno de Estado de Durango y Miguel Ángel Porrúa, Eds.). Ciudad de México: Miguel Ángel Porrúa.

Verduzco, G. (2003). Organizaciones no lucrativas: visión de su trayectoria en México. (Colegio de México : Centro Méxicano para Filantropía, Ed.). Ciudad de México. Disponible en https://doi.org/10.2307/j.ctv6jmxwg

Villalobos, J. y Cortés, L. (2015). Compendio Estadístico del Sector no lucrativo. México D.F.: Centro Mexicano de la Filantropía A.C. Disponible en www. cemefi.org

Villalobos, J. (2010). Filantropía y acción solidaria en la historia de México. (G. C. /CEMEFI Jorge Villalobos, Gabriel Loera, Ed.). Ciudad de México: DGE Equilibrista. 


\section{Sobre la autora María del Mar Sanz Abbud}

Doctora en Diseño por la Pontificia Universidad Católica de Río de Janeiro, cuenta con la Maestría en Diseño Estratégico en Innovación por la Universidad Iberoamericana, Ciudad de México y la licenciatura en Diseño Gráfico otorgada por la Universidad Iberoamericana, Ciudad de México. Obtuvo el primer lugar en el XIII Premio a la Investigación sobre la Sociedad Civil en la categoría de Tesis Doctoral, realizado por el Centro Mexicano de Filantropía CEMEFI en el año 2017. Forma parte del claustro de profesores de tiempo en la Universidad Iberoamericana, Ciudad de México desde el año 2010. Se ha desempeñado como coordinadora de la licenciatura en Diseño Gráfico de 2010 a 2015. Posteriormente, tomó la coordinación de Proyectos de Vinculación en el Departamento de Diseño. A partir del año 2017, representa al Departamento de Diseño ante el CENEVAL y forma parte del comité editorial de la Revista DIS, en la Universidad Iberoamericana. Actualmente su línea de investigación se enfoca en organizaciones del tercer sector para la generación de soluciones estratégicas desde un enfoque en la comunicación visual. 